\title{
Scuttle flies (Diptera: Phoridae) whose larvae develop in flowers of Aristolochia (Aristolochiaceae) in Panama
}

\author{
R. HENRY L. DISNEY ${ }^{1}$ and Sноко SAKAI ${ }^{2 *}$ \\ ${ }^{1}$ University Museum of Zoology, Downing Street, Cambridge CB2 3EJ, England. e-mail: rhld2@hermes.cam.ac.uk \\ ${ }^{2}$ Smithsonian Tropical Research Institute, Apartado 2072, Balboa, Ancon, Republic of Panama
}

Keywords. Diptera, Phoridae, new species, new synonymy, new combinations, Aristolochiaceae, Neotropical Region

\begin{abstract}
Megaselia metropolitanoensis Disney, sp. n., M. sakaiae Disney, sp. n. and Puliciphora pygmaea (Borgmeier, 1960) comb. n. are reported developing in the flowers of Aristolochia inflata H. B. K. and A. maxima Jacq. in Panama. The new species are described, as is the hitherto unknown male of Puliciphora pygmaea. The latter is transferred to the the genus Puliciphora Dahl, 1897 from the genus Myrmomyia Silvestri, 1911 which is formally synonymised with Puliciphora, along with $P$. brachymyrmecis (Silvestri, 1911) comb. n. and P. nigroflava (Borgmeier, 1958) comb. n.
\end{abstract}

\section{INTRODUCTION}

Hime \& Costa (1985) reported that the scuttle fly Megaselia aristolochiae Prado (in Hime \& Costa, 1985) (Diptera: Phoridae) develops in the flowers of Aristolochia labiata Willd. (Aristolochiaceae) in Brazil. We now report three further species of scuttle fly developing in the flowers of two other species of Aristolochia in Panama. Two of the fly species are previously undescribed and the male of the third was previously unknown and its generic assignment was considered doubtful. The new species and the hitherto unknown male are described and the generic assigment of the latter resolved.

\section{MATERIALS AND METHODS}

The study site was a seasonally dry forest in the Parque Natural Metropolitano near Panama City, Panama. Average annual rainfall at the site is $1740 \mathrm{~mm}$, most of which occurs during the rainy season from May to December. The forest is 80 year-old second growth of $40 \mathrm{~m}$ in height.

The phorids reported below were breeding in flowers of Aristolochia maxima Jacq. and $A$. inflata H.B.K. (Aristolochiaceae) from October to December in 1999 and 2000. Aristolochia is the most diverse genus of the family Aristolochiaceae with $\sim 350$ species distributed throughout the world, mainly in the tropics and subtropics. Their zygomorphic flowers are diverse in size, shape and color, but based on the same groundplan (Endress, 1994). Three sepals of the flower are united into an urceolate trap, in which three parts can be distinguished. The basal part is a chamber (utricle) that encloses the fused styles, stigmas, and anthers (collectively known as the gynostemium). The utricle is connected to a tube ending with an expanded limb, which is often colorful and thought to attract pollinators visually. In $A$. maxima, the chamber is $\sim 3.5 \mathrm{~cm} \times 2.0 \mathrm{~cm}$ and the limb is obovate, $\sim 4.5 \times 3.2 \mathrm{~cm}$, and purple with yellow patches. Most flowers occur on thin stems in the canopy layer, but inflorescences also occur on thick ( $3 \mathrm{~cm}$ in diameter), leafless stems near the ground. A. inflata has smaller flowers with a yellow limb of $\sim 3.6 \times 1.7 \mathrm{~cm}$ and a utricle measuring $\sim 1.3 \times 1.0 \mathrm{~cm}$.
In all Aristolochia species studied so far, flies of different families, including Anthomyiidae, Phoridae, Syrphidae, Chloropidae, Milichiidae and Sarcophagidae, have been recorded as pollinators (Cammerloher, 1923; Petch, 1924; Brues, 1928; Lindner, 1928; Brantjes, 1980; Costa \& Hime, 1983; Wolda \& Sabrosky, 1986; Hall \& Brown, 1993). On the day the protogynous flowers open, they attract flies and trap them inside the chamber. On the second day, the anthers dehisce and the flies are released with their pollen loads. Although flowers of some species produce a strong smell of carrion or feces, only a faint unpleasant odor is perceptible in A. maxima and A. inflata. In some species nectaries are found on the inner wall of the chamber (Cammerloher, 1923; Costa \& Hime, 1983) or at the floral entrance (Daumann, 1959; Vogel, 1998).

Flowers collected directly from inflorescences and flowers fallen from the forest floor were kept in plastic containers with wet sand for a month or more to obtain adults of the insects breeding in the flowers.

\section{RESULTS}

We deal with the taxonomy of the scuttle flies before proceeding to report on their natural histories.

\section{SYSTEMATICS (by R.H. L. Disney)}

A key to genera and the literature required for the identification of Neotropical Phoridae is provided by Disney (1994), with only the immediately relevant literature being cited below.

\section{Megaselia metropolitanoensis Disney, sp. n.}

(Figs 1-4)

Diagnosis. Mesopleuron bare; costal index $>0.5$; scutellum with four bristles, but the anterior pair shorter and finer than posterior pair; hind tibia without differentiated anterodorsal hairs; lower supra-antennal bristles (SAs) shorter and weaker than upper pair; female abdominal tergite 4 not modified; thoracic scutum, subglobose third antennal segment and haltere knob yellow; frons with

* Present address: Graduate School of Human and Environmental Studies, Kyoto University, Sakyo, 606-8501, Japan 


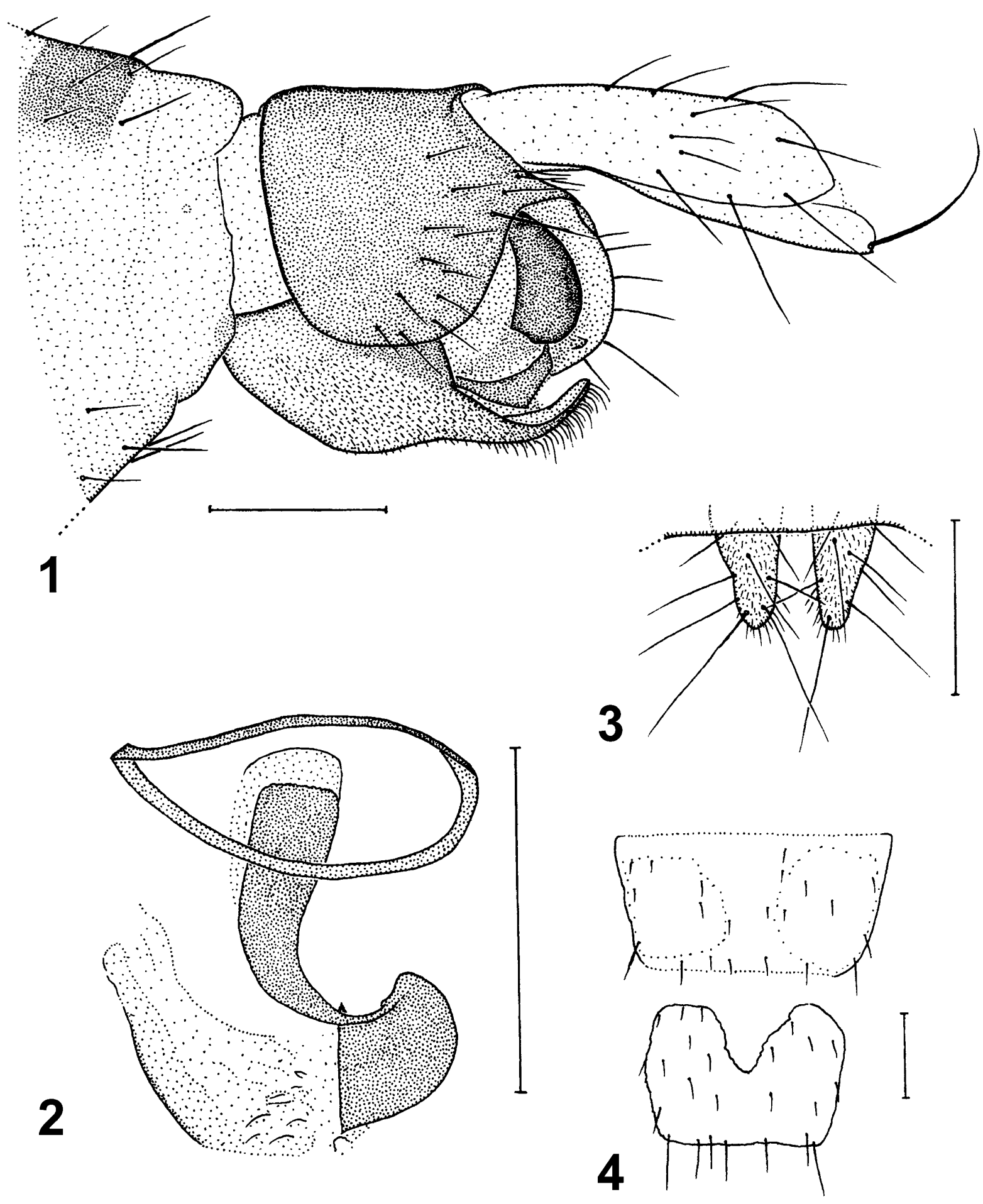

Figs 1-4: Megaselia metropolitanoensis Disney, sp. n. 1 - left face of male hypopygium; 2 - furca of female; 3 - posterolateral lobes of female abdominal sternum $8 ; 4-$ female abdominal tergites 5 and 6 . Scales: $0.1 \mathrm{~mm}$.

numerous fine microsetae; costal cilia abour $0.06 \mathrm{~mm}$ long; end of costa about level with tip of vein 3 ; front basitarsus not thickened; and oversall length $>2 \mathrm{~mm}$.

Male. Frons broader than long, brownish orange to brown with a darker ocellar triangle, and with $60-80$ hairs. Lower SAs at most half as long as upper pair. Upper SAs closer together than pre-ocellars (POs). Antials about level with upper SAs and a little closer to them than to anterolaterals (ALs) or almost equidistant, but ALs distinctly higher on frons. POs level with or slightly lower than mediolaterals (MLs) and range from being closer to each other than to an ML to the reverse. With 1-3 small bristles on cheek and a pair of long bristles on jowl. Third antennal segment lacks subcuticular pit sensilla (SPS) vesicles. The two segmented palp pale yellow but the distal segment variably lightly tinged 
brown, with 6-7 bristles (of which 2-3 are longer than rest) and almost twice as many hairs. Yellowish brown labrum with greatest breadth at most $0.6 \mathrm{x}$ that of third antennal segment. Darker labella with only a few spinules below. Each side of thoracic scutum with a humeral, two notopleurals (and no cleft), an intra-alar, a postalar and a prescutellar dorsocentral bristle. Scutellum yellowish brown. Legs pale straw yellow apart from brown tip of hind femur. All five fore tarsal segment with a posterodorsal hair palisade. Segment 5 slightly shorter than 3 but longer than 4. Hair palisade of mid tibia extends about $0.8 \mathrm{x}$ its length. Hairs below basal half of hind femur subequal to or slightly shorter than those of anteroventral row of distal half. Hind tibia with $8-10$ posterodorsals, the uppermost 3-4 being finer and the last being the longest and most robust. Spinules of apical comb all simple. Wing 1.3-1.5 mm long. Costal index 0.51-0.54.

Costal ratios 5.1-6.3:3.8-5.2: 1. Costal cilia 0.05-0.06 $\mathrm{mm}$ long. Axillary ridge with 3-4 short bristles, the outermost longer than costal cilia. No hair at base of vein 3 . Vein Sc not reaching R1. Veins brown, but 7 paler and its basal third only discernible with critical lighting. Membrane very lightly tinged grey. Abdomen with tergites $1-4$ and 6 largely brown but with a variably developed median longitudinal yellow band on $1-4$, and T2 and T6 with anterior thirds variably yellow. T5 entirely yellow or with variable patches of brown pigment, especially anterolaterally. With sparse small hairs, which are a little longer at rear of T6, and 3-5 small bristles towards sides of T2. Venter straw yellow with scattered hairs below segments 3-6. Hypopygium brown, with whitish yellow anal tube variably tinged brown in basal half, and as Fig. 1. Right hypandrial lobe shorter than left lobe.

Female. Head similar to male except labrum is $1.2-1.4 \mathrm{x}$ as broad as third antennal segment. Thorax as male except anterior scutellars are more obviously bristle like. Legs as male. Wing 1.6-1.7 mm long. Costal index $0.52-0.59$. Costal ratios 5.3-6.5:4.1-4.6:1. Costal cilia $0.06 \mathrm{~mm}$ long. Otherwise as male. Abdomen with tergites 1-5 yellow with large brown patches either side of midline yellow stripe. These patches extend to lateral margins but not to front and hind margins. T5-T6 as Fig. 4, T6 being entirely brown but with anterior median V-shaped grey notch. Near sides of T2 there are 2-5 small bristles. Otherwise hairs small and sparse, apart from distinctly longer hairs at rear of T6. Venter as male but hairs below tend to be stronger, especially at rear of segment 6; and there are grey bands extending from the brown edges of tergites on 2-5, and segments 6 onwards tend to be generally grey. Cerci white, twice as long as broad, and with eight hairs of which a pre-apicalis $1.5 \mathrm{x}$ as long as cercus. With finger-like posterolateral lobes on sternum 8 (Fig. 3). Internally furca as Fig. 2; with four rectal papillae; and Dufour's crop mechanism elongated ovoid, with rounded posterior end bearing a small blunt lobe at its tip.

Type locality. Panama, Parque Natural Metropolitano, Panama City.

Type material. Holotype male, Panama, Parque Natural Metropolitano, Panama City, secondary forest, ex Aristolochia maxima flowers, xi. 2000, S. Sakai (University Museum of Zoology, Cambridge). Paratypes: 4 males, 2 females, same data as holotype.

Etymology. Named after the type locality.

Affinities. In the keys of Borgmeier (1962) this species will run to couplet 55 lead 2 on page 307 or to couplets 83,85 or 92 lead 1 on page 311 . The yellow third antennal segment and haltere knob will distinguish it from the species of these couplets. At couplet $85 \mathrm{Msub}$ flava (Malloch, 1912) is incorrectly stated to have yellow third antennal segments. However, this species was subsequently redescribed by Borgmeier (1969). The only subsequently described species running to the same couplets is $M$. aristolochiae, which is clearly closely related. However it has brown halteres, a shorter dorsal face of the epandrium and the hairs below the basal half of the female hind femur are only a little differentiated from those of the anterior face.

Megaselia sakaiae Disney, sp. $\mathrm{n}$.

\section{(Figs 5-8)}

Diagnosis. Mesopleuron bare; costal index 0.47-0.52; scutellum with anterior pair of small hairs and posterior pair of bristles; hind tibia without differentiated anterodorsal hairs; frons with dense, but fine, microsetae; female abdominal tergites normal, uniformly brown and T6 broader than long; costal cilia $<0.1 \mathrm{~mm}$ long; with only one pair of supra-antennal bristles (SAs); haltere brown; subglobose third antennal segment yellowish brown; hind femur brown; anal tube long and midline length of epandrium very short; palp bristles a little longer than greatest breadth of palp; wing $<2 \mathrm{~mm}$ long; and female labrum inflated.

Male. Frons broader than long, brown and with 24-50 hairs. Antials midway between anterolaterals (ALs) and SA bristles or slightly closer to SAs, and level with these bristles or ALs a little higher on frons. Pre-ocellars (POs) closer together than either is from a mediolateral, which is level with POs or a little lower on frons. With 0 or 1 small bristle on cheek and two longer bristles on jowl. Palps yellowish brown to straw yellow, with 5-7 bristles (of which only 1-3 are a little longer than greatest breadth of palp) and half as many hairs. Basal segment not clearly demarcated as in $M$. metropolitanoensis. Pale dusky yellow to yellowish brown labrum at most two thirds width of third antennal segment. Pale brown labella somewhat short and almost devoid of spinules below. Thorax brown. Each side of scutum with a humeral, two notopleurals (and no cleft); an intra-alar, a postalar and a prescutellar dorsocentral bristle. Mid and hind coxae, femora and tibiae largely brown, those of front leg brownish yellow and tarsi mainly pale yellow. All five fore-tarsal segments with a posterodorsal hair palisade. Segment 5 longer than 3, which is longer than 4 . Neardorsal hair palisade of mid tibia extends about two thirds of length. Hairs below basal half of hind femur clearly longer and stronger than those of anteroventral row of outer half. Hind tibia typically with eight differentiated hairs, of which the fifth is stronger than the rest except for the more spine-like last (pre-apical). Spinules of apical 

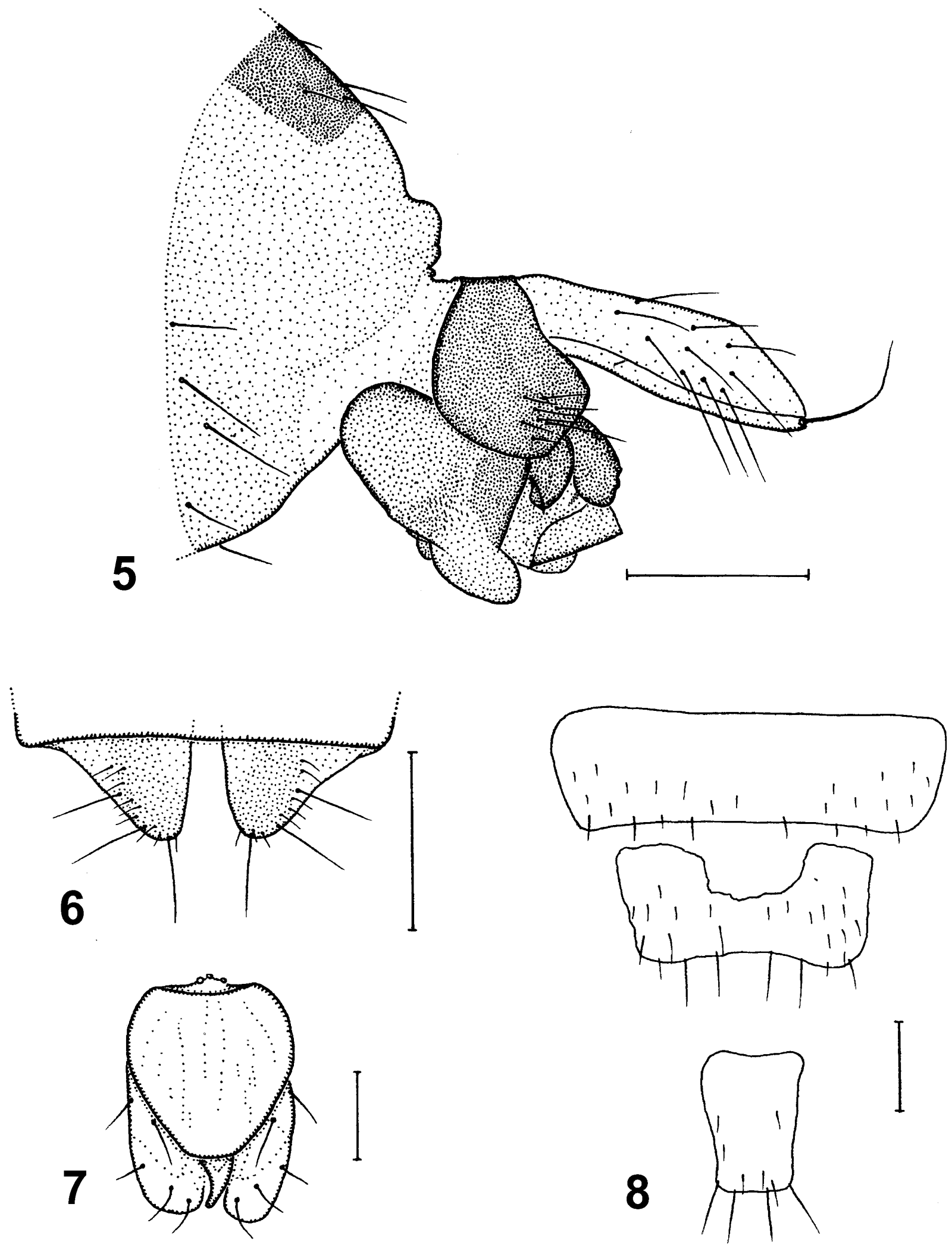

Figs 5-8: Megaselia sakaiae Disney, sp. n. 5 - left face of male hypopygium; 6 - posterolateral lobes of female abdominal sternum $8 ; 7$ - female proboscis; 8 - female abdominal tergites $5-7$. Scales: $0.1 \mathrm{~mm}$.

comb all simple. Wings $1.0-1.8 \mathrm{~mm}$ long. Costal index $0.47-0.50$. Costal ratios $3.3-4.6: 2.7-4.1: 1$. Costal cilia $0.05-0.07 \mathrm{~mm}$ long. Axillary ridge with $2-3$ (usually 3 ) bristles, the outermost being clearly longer than costal cilia. No hair at base of vein 3. Sc fading away well before R1. Veins pale brownish grey, but 4-6 paler and 7 


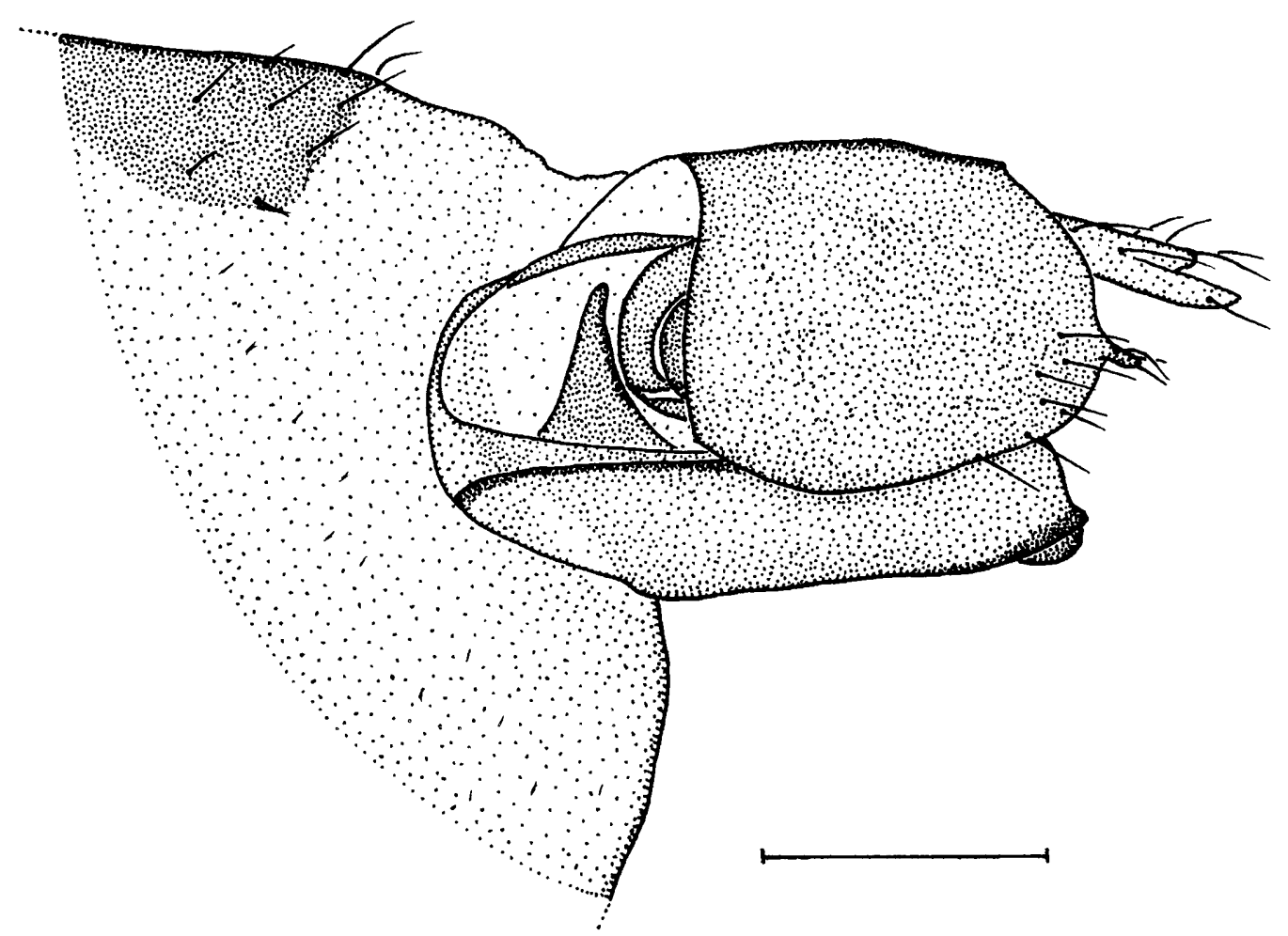

Fig. 9. Puliciphora pygmaea (Borgmeier) male, left face of hypopygium. Scale: $0.1 \mathrm{~mm}$.

only discerned with critical lighting. Membrane only very lightly tinged grey. Abdominal tergites brown with short sparse hairs, which are only a little longer at rear of T6. Venter brown with a few small hairs below segments 3-6. Hypopygium brown with a whitish yellow anal tube, which is variably tinged brown in basal quarter, and as Fig. 5. Right lobe of hypandrium very short.

Female. Frons similar to male but with 30-62 hairs. With $0-2$ cheek bristles. Palps with stronger bristles and twice as many hairs. The orange brown labrum inflated (Fig. 7), being up to $1.7 \mathrm{x}$ as wide as third antennal segment. Thorax and legs as male. Wing 1.1-1.4 mm long. Costal index 0.48-0.52. Costal ratios 2.9-5.2 : 2.2-4.7 : 1. Costal cilia $0.06-0.09 \mathrm{~mm}$ long. Otherwise as male. Abdominal tergites brown. T5-T7 as Fig. 8. Venter brown with hairs below segments 3-6, those at rear of 6 being longer than rest. The whitish, lightly tinged brown, cerci short (about 1.6x as long as broad) with eight hairs, the longest being about $2.5 \mathrm{x}$ as long as cercus. Brown posterolateral lobes of sternum 8 as Fig. 6. Internally Dufour's crop mechanism pear shaped, pale and rounded behind; an ovoid sclerotised furca and at least two rectal papillae.

Etymology. Named after Shoko Sakai.

Type locality. Panama, Parque Natural Metropolitano, Panama City.

Type material. Holotype male, Panama, Parque Natural Metropolitano, Panama City, secondary forest, ex Aristolochia inflata flower, xi. 2000, S. Sakai (in University Museum of Zoology, Cambridge). Paratypes: 5 males, 6 females - all on slides, plus 26 specimens in alcohol, as holotype except some ex A. maxima flowers.

Affinities. In the keys of Borgmeier (1962) this species runs to couplet 51 lead 2 on page 309. It differs from $M$. ferruginosa (Brues, 1912) in having much stronger (upper) SA bristles and lacking small lower SA hairs; and the male has a very much longer anal tube. The male of the subsequently described $M$. darlingtonae Disney, 1995 also has a much shorter anal tube and has the palp bristles greatly reduced in size. Otherwise $M$. sakaiae most resembles the subsequently decribed $M$. aristolochiae. However, the female of the latter has extensive yellow patches on the abdominal tergites. Its male has stronger anterior scutellars, a pair of small lower SA bristles and fewer hairs on the left side of the epandrium. The inflated labrum of the female closely resembles that of the subsequently described M. graminicola (Borgmeier, 1969), which runs to couplet 50 by virtue of its yellow halteres. It further differs from $M$. sakaiae in having abdominal tergite 6 longer than broad and strongly tapered towards the rear.

Puliciphora pygmaea (Borgmeier, 1960) comb. n. Myrmomyia pygmaea Borgmeier, 1960: 342.

(Fig. 9)

It has previously been suggested (Disney, 1994) that the genus Myrmomyia Silvestri, 1911 is only doubtfully distinct from Puliciphora Dahl, 1897. The three included species have hitherto been only known in the female sex. The procurement of the previously unknown male of 
Myrmomyia pygmaea, which is described below, reinforces this opinion.

Borgmeier (1960) provided the most recent diagnosis for Silvestri's genus, and distinguished it from Puliciphora females on the basis of the relatively large eyes and the lack of an alar bristles and its adjacent subcircular, papilla-like, wing vestige. In his description of $M$. pygmaea he reported six bristles at the rear margin of the thoracic dorsum. However, the slide mounting of females has revealed that adjacent to each of the outer pair of these bristles there is a wing vestige; but it lies largely beneath the surface of the integument and is therefore likely to be overlooked in specimens that are not slide mounted. It follows that the outer pair of bristles must be reinterpreted as being a pair of alar bristles. The wing rudiments, being still largely invisible externally, probably constitute a case of heterochrony. The relatively large eyes not only represent a difference of degree only but are clearly a symplesiomorphy, and therefore of no significance in classification. The male of $M$. pygmaea (see below) is entirely consistent with the generic diagnosis for Puliciphora, as given by Borgmeier (1963). It is concluded that the case for treating Myrmomyia as a distinct genus cannot be sustained. It is therefore herewith synonymised with Puliciphora. (Syn. n.).

In Borgmeier's (1960) key to Neotropical Puliciphora females $P$. pygmaea will run to couplet 11 lead 1 . It is immediately distinguished from $P$. coprophila Borgmeier, 1960 by the absence of the posterior part of abdominal tergite 5. The females of $P$. brachymyrmecis (Silvestri, 1911) comb. nov. and $P$. nigroflava (Borgmeier, 1958) comb. nov. will both run to couplet 2 lead 1 . They are immediately distinguished from $P$. convexa Borgmeier, 1960 by the lack of abdominal tergite 6 . P. brachymyrmecis also lacks the posterior part of $\mathrm{T} 5$, in contrast to $P$. nigroflava. In the females of $P$. pygmaea there is also no T6 visible externally, but its anterior apodemes are still present beneath the integument. The male of this species is described below.

Male. Frons brown, clearly wider than long, with dense but minute microsetae, and 30-44 hairs. Four subequal supra-antennal bristles (SAs), the upper pair about as far apart as each is from an anterolateral, which is slightly higher on frons. Pre-ocellars further apart than upper SAs and also than either is from a mediolateral, which is a little lower on frons. With two bristles on cheek and 5-7 on jowl. Subglobose third antennal segment brown with a single large SPS vesicle beneath inner face and sometimes a smaller one (about as large as SA socket) near lower face. Pale brown palps with 5-7 bristles (the apical one being longest) and at least as many hairs. Pale yellowish brown labrum only about $0.4 \mathrm{x}$ as wide as third antennal segment. Labella also pale brown, narrowing apically and with only a few small spinules below. Thorax brown. Each side of scutum with three notopleurals, an intra-alar, a postalar and a prescutellar dorsocentral bristle. Scutellum with an anterior pair of fine hairs and a posterior pair of bristles. Legs with pale brown femora and tibiae and paler tarsi. Only first four front tarsal segments with a posterodorsal hair palisade. Hind basitarsus with 4-5 complete transverse combs and an apical row of three spines. Wing 1.0-1.1 mm long. Costal index $0.52-0.56$. Costal ratios $0.67-0.74: 1$. Thick veins pale brown. Membrane very lightly tinged brownish grey. Haltere with dark brown knob but pale stem. Abdomen with brown tergites with sparse small hairs. Venter brown with sparse small hairs below segments 3-6. Hypopygium brown with pale brown anal tube and as Fig. 9.

Material examined. Panama, Parque Natural Metropolitano, Panama City, secondary forest, 4 males, xi. 2000, ex Aristolochia maxima flowers; 23 males, 7 females, 23.xii.2000, ex A. maxima floweres, 1 male, 2 females, ex $A$. inflata flowers, 10 females caught on $A$. maxima flowers.

\section{NATURAL HISTORY (by Shoko Sakai) \\ Megaselia metropolitanoensis}

The species probably oviposits on flowers of $A$. maxima only after they have been shed. None emerged from flowers collected from inflorescences. Successful rearings were from those collected from the forest floor. However, no adults were observed in the field. Of 12 individuals that emerged, nine were female.

\section{Megaselia sakaiae}

The species was the most abundant insect found in utricles of living flowers of $A$. maxima and $A$. inflata. Most were female (375 individuals out of 376 in $A$. maxima and all of 108 in $\mathrm{A}$. inflata). Movements of flies between flowers mostly occurred from 6:00 to 7:00 in the morning in $A$. inflata and earlier in $A$. maxima. $M$. sakaiae in flowers of the both Aristolochia species were observed to lick nectar secreted from hairs on the inner surface of the utricle. They oviposited on the inner surface of a floral limb and the inside of a utricle in $A$. maxima. In $A$. inflata, eggs were found only inside utricles, especially on gynostemia. Visits of the species to fallen flowers were not observed.

Larvae seemed to emerge from the eggs within a couple of days. They fed on petals and gynostemia, which gradually changed to black, thus suggesting they were progressively rotting. Under these rearing conditions, they often pupated on the wall of the plastic container or less frequently on rotten flowers. About 15 days after oviposition, adults emerged from puparia in the daytime. The ratio of males of the emerging adults was $46 \%(\mathrm{~N}=$ 527).

\section{Puliciphora pygmaea}

The flightless females were frequently observed on shed flowers of A. maxima and A. inflata on the forest floor, but rarely observed on flowers on inflorescences. They were reared only from flowers collected from the forest floor.

\section{DISCUSSION}

The flightless females of Puliciphora pygmaea are probably transported to the fallen flowers of Aristolochia by the males during nuptial flights, as has been reported 
for other members of this genus of flies (Miller, 1979; Disney, 1994).

ACKNOWLEDGEMENTS. SS thanks Michael Libsch for help in collecting flies; and Drs. S. Joseph Wright and David W. Roubik for invaluable support for the fieldwork in Panama which was supported by JSPS Postdoctoral Fellowships for Research Abroad. RHLD's studies of Phoridae are supported by the Isaac Newton Trust (Trinity College, Cambridge)

\section{REFERENCES}

BorgmeIER T. 1960: Gefluegelte und ungefluegelte Phoriden aus der neotropischen Region, nebst Beschreibung von sieben neuen Gattungen (Diptera, Phoridae). Studia Ent., (Petropolis) 3: 257-374.

BORGMEIER T. 1962: Versuch einer Uebersicht ueber die neotropischen Megaselia-Arten, sowie neue oder wenig bekannte Phoriden verschiedener Gattungen (Dipt. Phoridae). Studia Ent., (Petropolis) 5: 289-488.

BorgmeIER T. 1963: Revision of the North American phorid flies. Part I. The Phorinae, Aenigmatiinae and Metopininae, except Megaselia (Diptera, Phoridae). Studia Ent., (Petropolis) 6: 1-256.

Borgmeier T. 1969: New or little-known Phorid flies, mainly of the Neotropical Region (Diptera, Phoridae). Studia Ent., (Petropolis) 12: 33-132.

Brantues N.B.M. 1980: Flower morphology of Aristolochia species and consequences for pollination. Acta bot. neerl. 29 212-213.

Brues C. T. 1928: Some Cuban Phoridae which visit the flowers of Aristolochia elegans. Psyche 35: 160-161.

CAMmerloher H. 1923: Zur Biologie der Blüte von Aristolochia grandiflora Swartz. Öst. bot. Z. 72: 180-198.
Costa E. DE L. \& Hime N. DA C. 1983: Observações sobre a biologia floral de Aristolochia macroura Gomez (Areistolochiaceae). Atas Soc. Bot. Bras. (Rio de J.) 1: 63-66.

DAHL T. 1897: Puliciphora, eine neue flohaenliche Fliegengattung. Zool. Anz. 20: 405-412.

Daumann E. 1959: Zur Kenntnis der Blütennektarien von Aristolochia. Prestia 31: 359-372.

Disney R.H.L. 1994: Scuttle Flies: The Phoridae. Chapman \& Hall, London, xii +467 pp.

ENDREss P.K. 1994: Diversity and Evolutionary Biology of Tropical Flowers. Cambridge University Press, Cambridge, xiv +511 pp.

Hall D.W. \& Brown B.V. 1993: Pollination of Aristolochia littoralis (Aristolochiales: Aristolochiaceae) by males of Megaselia spp. (Diptera: Phoridae). Ann. Ent. Soc. Am. 86: 609-613.

Hime N. DA C. \& CostA E. DE L. 1985: On Megaselia (M.) aristolochiae n. sp. (Diptera, Phoridae) with larvae rearing on the flowers of Aristolochia labiata Willd. (Aristolochiaceae). Revta. Bras. Biol. 45: 621-625.

LINDNER E. 1928: Aristolochia lindneri Berger und ihre Bestäubung durch Fliegen. Biol. Zbl. 48: 93-101.

MiLleR P.L. 1979: Intraspecific phorid phoresy. Entomologist's Mon. Mag. 114: 211-214.

Petch T. 1924: Notes on Aristolochia. Ann. R. Bot. Gdns, Peradeniya 8: 1-108.

SILVESTRI F. 1911: Contributo alla conoscenza dei mirmecofili del Messico. Boll. Lab. Zool. Gen. Agr. R. Scuola Agric., (Portici) 5: 172-195.

VOGEL S. 1998: Remarkable nectaries: structure, ecology, organophyletic perspectives II. Nectaries. Flora 193: 1-29.

Wolda H. \& SABrosky C.W. 1986: Insect visitors to two forms of Aristolochia pilosa in Las Cumbres, Panama. Biotropica 18: 295-299.

Received March 26, 2001; revised June 12, 2001; accepted July 3, 2001 